\title{
ОПЫТ ОБУЧЕНИЯ СТУДЕНТОВ ВУЗА ФОРМИРОВАНИЮ ОТЧЕТОВ И СОЗДАНИЮ ПРЕЗЕНТАЦИЙ
}

\section{MODERNIZATION OF HIGHER EDUCATION: EXPERIENCE OF TRAINING STUDENTS TO FORM REPORTS AND CREATE PRESENTATIONS}

\section{O. Bolbat \\ E. Zakirova \\ O. Hekalo}

Summary: This article describes the experience of introducing the elective discipline "Reporting and Making Presentations" into the educational process at the Siberian Transport University (Novosibirsk) in accordance with the curriculum of 03.03.01 "Advertising and Public Relations" training direction. The analysis of the discipline content is presented in this article. The authors have developed the system of tasks being aimed at the forming of appropriate competencies should be mastered by the students when studying the educational program. Moreover, an electronic support of the discipline in the educational space of the University is described in the article. This article has been prepared with the support of the Russian Foundation for Basic Research (RFBR), project №18-012-00395.

Keywords: university, academic discipline, reporting, presentation creating.

«Самое главное богатство в нашей жизни результаты наших достижений» Томас Генрих Хаксли

Слова известного английского ученого можно отнести к деятельности любого современного предприятия. Полноценное информирование общества о достижениях предприятия или организации возможно благодаря современным технологиям, позволяющим правильно разработать отчет и профессионально донести до целевой аудитории достоверную информацию, например, с помощью доклада и презентации.

Результаты проведенного нами анализа рабочих программ дисциплин, входящих в учебные планы факультетов «Инженерно-экономический», «Управление персоналом», «Мировая экономика» и «Управление транспортно-технологическими комплексами» ФГБОУ ВО «Сибирский государственный университет путей сообщения» показали, что студенты шести из семи направлений подготовки лишены возможности изучать теоре-
Болбат Ольга Борисовна

К.n.н., доцент, ФГБОУ ВО «Сибирский государственный университет путей сообщения» (2. Новосибирск) olgab2203@gmail.com

Закирова Елена Сергеевна Д.фрилол.н., профессор, ФГБОУВО «Московский государственный лингвистический университет» zes.64@mail.ru

Хекало Ольга Юрьевна

К.т.н., доцент, ФГБОУ ВО «Сибирский государственный университет путей сообщения» (2. Новосибирск) new_holga@mail.ru

Аннотация: Данная статья посвящена описанию опыта внедрения в образовательный процесс дисциплины «Формирование отчетов и создание презентаций» в ФГБОУ ВО «Сибирский государственный университет путей сообщения» по направлению подготовки 42.03 .01 «Реклама и связи с общественностью», входящей в перечень блока дисциплин по выбору. В статье представлен анализ содержания дисциплины, приведена разработанная авторами система заданий, нацеленных на формирование соответствующих компетенций, которыми студент должен овладеть в процессе освоения образовательной программы. Кроме того, приведен пример электронного сопровождения дисциплины в образовательном пространстве вуза. Статья подготовлена при поддержке Российского фонда фундаментальных исследований, проект №18-012-00395.

Ключевые слова: вуз, учебная дисциплина, формирование отчетов, создание презентаций, компетенции.

тические и практические основы создания презентаций и формирования отчетов. Следует отметить, что для студентов, осваивающих инженерные специальности и обучающихся по целевым направлениям при поддержке Западно-Сибирской железной дороги, введена дисциплина «Основы эффективных презентаций», успешное освоение студентами которой подтверждается на практике. Кроме того, при изучении данной проблемы анализировались итоги защиты выпускных квалификационных работ студентами бакалавриата. В отчетах председателей государственных аттестационных комиссий имелись замечания, указывающие на низкое качество презентации проектов. Таким образом, стала очевидной необходимость освоения студентами компетенций, отвечающим требованиям, предъявляемым к современным выпускникам высшего учебного заведения и запросам работодателя.

Считаем, что внедрение в учебный процесс дисциплины «Формирование отчетов и создание презентаций» является актуальным для высших учебных заве- 
дений. Следует отметить, что в ФГБОУ ВО «Сибирский государственный университет путей сообщения» данная дисциплина введена в учебный процесс для студентов бакалавриата, обучающихся по направлениям 42.03 .01 «Реклама и связи с общественностью» и 38.03 .04 «Государственное и муниципальное управление». В качестве эксперимента разработанный авторами метод обучения студентов созданию презентаций также применялся в учебном процессе в рамках дополнительного образования по программам переподготовки на иностранном языке в ФГБОУ ВО «Московский политехнический университет», ФГБОУ ВО «Всероссийский государственный университет юстиции (РПА Минюста России)».

Необходимость внедрения данной дисциплины в образовательный процесс и учебные планы ФГБОУ ВО «Сибирский государственный университет путей сообщения» инициировалась кафедрой «Государственное и муниципальное управление» в результате взаимодействия со специалистами в области статистики и представителями административно-управленческого аппарата предприятий, крупных компаний, организаций. Далее преподавателями кафедры «Графика» с целью изучения мнения обучающихся было проведено анкетирование, в котором приняли участие 378 студентов факультета «Управление персоналом», изучающих дисциплину «Формирование отчетов и создание презентаций». В содержание анкеты входили следующие вопросы:

\section{Анкета}

Дисциплина «Формирование отчетов и создание презентаций» глазами студента

1. Считаете ли Вы полезным и необходимым изучение дисциплины «Формирование отчетов и создание презентаций»?

а) да;

б) нет;

в) затрудняюсь ответить;

г) надеюсь, что полученные знания пригодятся в дальнейшей учебе.

2. Где, по Вашему мнению, можно использовать знания, полученные при изучении дисциплины «Формирование отчетов и создание презентаций»?

а) при подготовке к публичной защите курсовых работ;

б) при подготовке к выступлению на конференции и в НИРС;

в) для использования в личных целях;

г) при защите отчета по практике и ВКР.

Результаты анкетирования приведены ниже (рис. 1 и рис.2).

В настоящее время существует много программ, используемых для создания различной отчетной документации. Отметим некоторые из них, пробные версии которых имеют свободный доступ на сайтах разработчиков:

- программа подстановки данных из одного файла в другой (замена функции ВПР) - Lookup.xla;

- «Прайс лист» - программа объединения и обработки прайс листов - Unification.xla;

- Надстройка для вставки картинок (изображений) в Excel - PastePictures.xla;

- Программа создания документов Word и Excel по шаблонам -заполнение бланков (форм) FillDocuments.

Поскольку данная дисциплина преподается студен-

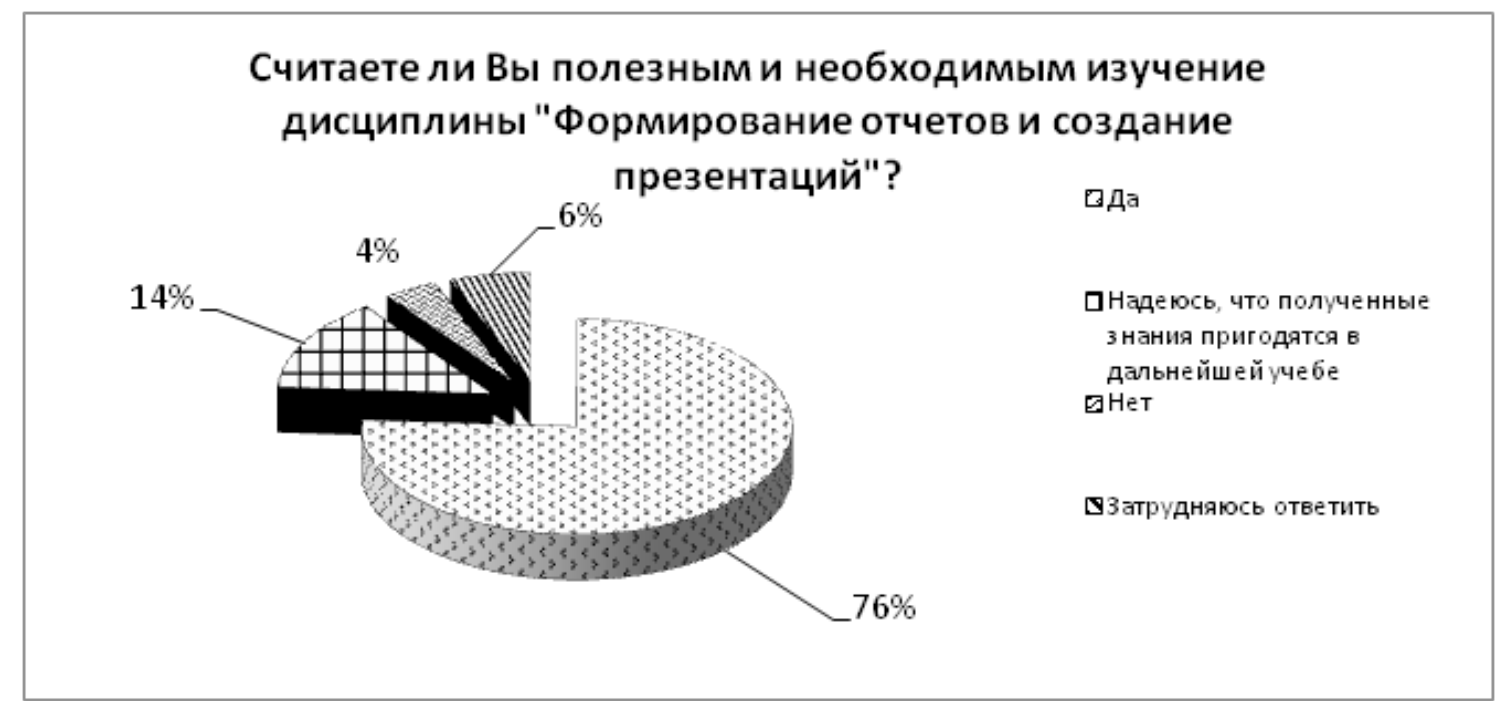

Рис. 1. Структура распределения ответов на вопрос анкеты 


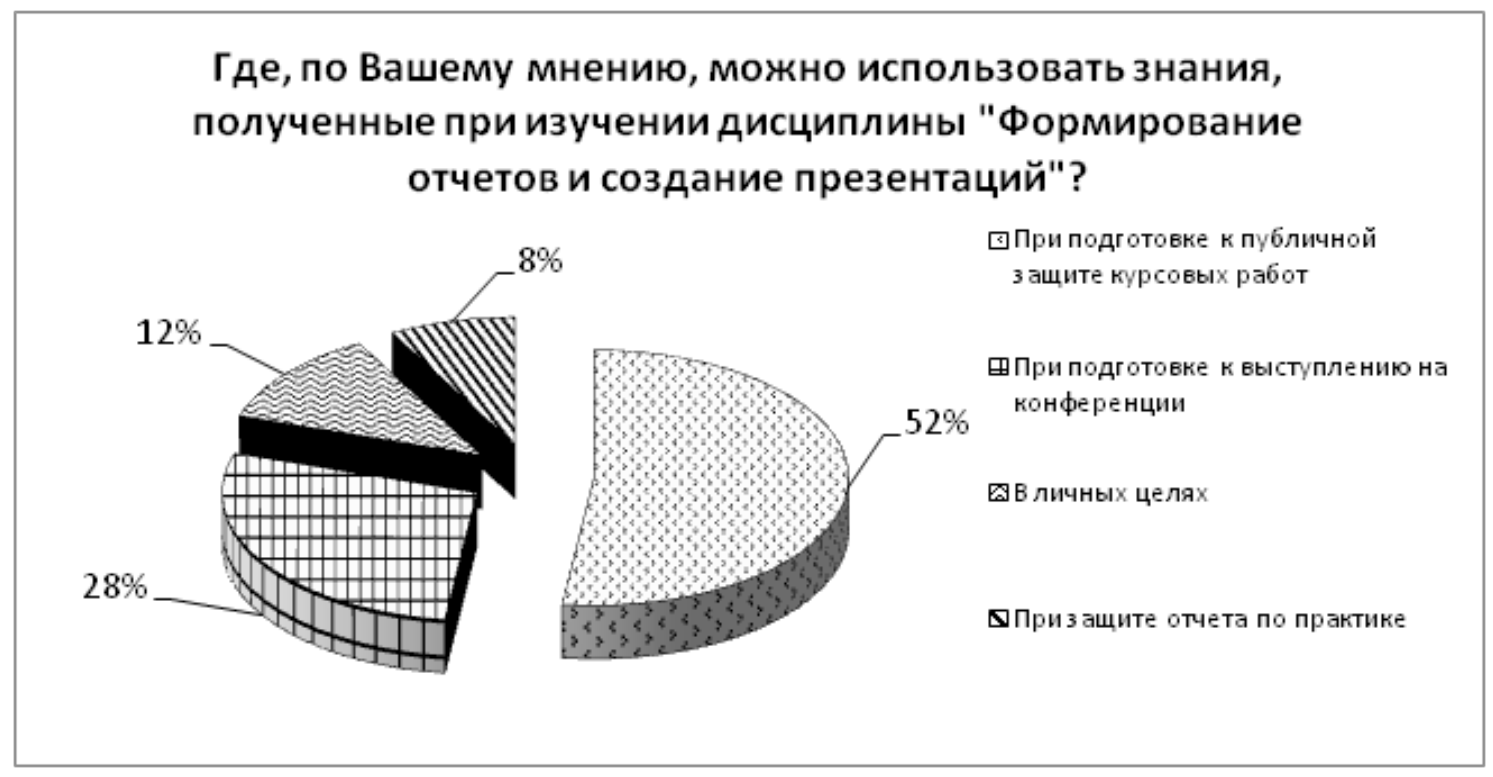

Рис. 2. Структура распределения ответов на вопрос анкеты

там первого курса, ведущими преподавателями было принято решение выбрать средства MS Office 2010 (Excel, Word) для создания деловой документации и формировании отчетов и MS PowerPoint использовать для создания презентаций [1].

Дисциплина «Формирование отчетов и создание презентаций» является новой и преподается достаточно недавно. Данная дисциплина обеспечивает логическую взаимосвязь графических дисциплин с профессиональными. Основной целью ее преподавания является знакомство с возможностями деловой презентационной графики и её использованием в будущей профессиональной деятельности, а также освоение технологии создания баз данных и основ формирования отчетов. Данная дисциплина относится к дисциплинам по выбору и изучается на 1 курсе в 1 семестре. На ее изучение отводится 108 часов, из них лекций - 16 часов, практических занятий - 34 часа и самостоятельная работа студентов 58 часов. Контактная работа с преподавателем составляет всего 50 часов. Это меньше, чем время, отведенное на самостоятельное изучение дисциплины.

Содержание данной дисциплины можно условно разделить на 3 раздела:

1. Основные правовые и нормативные документы и правила формирования отчетов.

2. Формирование отчетов и создание презентаций.

3. Знакомство с программными средствами.

Содержание лекционной части соответственно включает в себя следующие темы: «Виды отчетной документации»; «Основные правовые и нормативные документы»; «Знакомство с программными средствами».
На лекциях студенты знакомятся с:

- обзором программных средств, предназначенных для формирования отчетов;

- ГОСТ 7.1-2003 Система стандартов по информации, библиотечному и издательскому делу. Библиографическая запись. Библиографическое описание. Общие требования и правила составления;

- ГОСТ 7.9-95 (ИСО 214-76) Система стандартов по информации, библиотечному и издательскому делу. Реферат и аннотация. Общие требования;

- ГОСТ 7.12-93 Система стандартов по информации, библиотечному и издательскому делу. Библиографическая запись. Сокращение слов на русском языке. Общие требования и правила;

- ГОСТ 7.32-2001 Система стандартов по информации, библиотечному и издательскому делу. Отчет о научно-исследовательской работе. Структура и правила оформления.

Темы практических занятий условно можно разделить на две части: создание презентаций в PowerPoint и создание деловой документации, и формирование отчетов. Во время учебных занятий студенты изучают возможности деловой презентационной графики, виды и назначение отчетной документации, методы формирования отчетов, учатся создавать отчетную документацию, знакомятся с правилами оформления текстовых документов, учатся строить и редактировать динамичные графики, диаграммы и гистограммы, а также создавать и редактировать компьютерные презентации и формировать отчеты. Вся работа со студентами построена на углубленном изучении программ, входящих в стандартных пакет Microsoft Office. На практических занятиях студенты выполняют ряд индивидуальных заданий, знакомятся с созданием деловой документации и работой 
с документами MS Office 2010 (Excel, Word, PowerPoint), a также изучают основы формирования отчетов средствами MS Office 2010 (Excel, Word).

Процесс статистического исследования включает в себя три этапа. Наиболее важным и значимым является начальный этап, нацеленный на сбор информации. Значимость этого этапа объясняется тем, что достоверность собранной информации влияет как на результат всего исследования, так и на эффективность принятия управленческих решений. Практический опыт показывает, что особое место в системе сбора информации занимает отчетность, составление которой вызывает трудности в работе многих организаций из-за отсутствия или недостатка специальных знаний.

В ходе разработки рабочей программы по данной дисциплине в соответствии с образовательным стандартом и учебным планом по направлению подготовки 42.03.01 «Реклама и связи с общественностью» разработчиками был подобран учебный материал для лекционных и практических занятий, а также оценочные средства, нацеленные на формирование у студентов компетенций (УК-1, УК-2), содержание которых, включая перечень планируемых результатов обучения, представлены в таблице 1.

В дальнейшем знания, полученные в ходе изучения представленной дисциплины, могут применяться в таких блоках дисциплин учебного плана как:

Блок 1. «Дисциплины» - обязательная часть и часть, формируемая участниками образовательных отношений;

Блок 2. «Практика» - обязательная часть и часть, формируемая участниками образовательных отношений;

Блок 3. «Государственная итоговая аттестация» - подготовка к процедуре защиты и защита выпускной квалификационной работы и факультативы.
Решение задач, связанных с достижением высокой степени эффективности освоения данной учебной дисциплины и формированием у студентов указанных компетенций, потребовало от ведущих преподавателей разработать тесты в качестве оценочных средств по разделам «Формирование отчетов» и «Создание презентаций». Тесты проводятся во время трех контрольных сроков. При проведении текущего тестового контроля используется сто балльная шкала: 100 - 65 баллов - тест считается успешно выполненным; 64 балла и ниже - тест оценивается неудовлетворительно и требуется повторное тестирование.

Формой итоговой отчетности является зачет. К зачету допускаются студенты, выполнившие семестровый план работы в полном объеме, а именно:

- полностью выполнен план работы на учебных занятиях в течение семестра;

- успешно выполнено тестирование по разделам «Формирование отчетов» и «Создание презентаций» в течение семестра;

- успешно выполнены итоговые тесты по разделам «Формирование отчетов» и «Создание презентаций» В конце семестра.

Результаты обучения по данной дисциплине определяются оценочными средствами, приведенными в таблице 2.

Следует отметить, что эффективность освоения данной дисциплины также обеспечивается созданной в ФГБОУ ВО «Сибирский государственный университет путей сообщения» электронной учебно-образовательной средой с использованием системы Moodle на сайте http://moodle3.stu.ru [6], где ведущими преподавателями кафедры «Графика» разработан курс, включающий официальные документы, рабочие программы дисциплины и методические материалы, необходимые для выполнения индивидуальных заданий по данной дис-

Таблица 1

\begin{tabular}{|c|c|c|c|}
\hline $\begin{array}{l}\text { Код } \\
\text { компетенции }\end{array}$ & Наименование компетенции & $\begin{array}{l}\text { Индикаторы достижения компетен- } \\
\text { ции }\end{array}$ & Результаты обучения по дисциплине \\
\hline УK-1 & $\begin{array}{l}\text { Способен осуществлять поиск, кри- } \\
\text { тический анализ и синтез информа- } \\
\text { ции, применять системный подход } \\
\text { для решения поставленных задач }\end{array}$ & $\begin{array}{l}\text { УК-1.1 Выбор информационных ре- } \\
\text { сурсов для поиска информации в со- } \\
\text { ответствии с поставленной задачей }\end{array}$ & $\begin{array}{l}\text { Знать: информационные ресурсы поиска информации } \\
\text { Уметь: осуществлять поиск информации, обобщать, анали- } \\
\text { зировать и воспринимать информацию, ставить цель и вы- } \\
\text { бирать пути ее достижения Владеть: культурой мышления }\end{array}$ \\
\hline УК-2 & $\begin{array}{l}\text { Способен определять круг задач в } \\
\text { рамках поставленной цели и вы- } \\
\text { бирать оптимальные способы их } \\
\text { решения, исходя из действующих } \\
\text { правовых норм, имеющихся ресур- } \\
\text { сов и ограничений }\end{array}$ & $\begin{array}{l}\text { УК-2.4 Выбор правовых и норматив- } \\
\text { но технических документов, приме- } \\
\text { няемых для решения заданий про- } \\
\text { фессиональной деятельности }\end{array}$ & $\begin{array}{l}\text { Знать: правовые и нормативно-технические документы } \\
\text { научно-исследовательского обеспечения организационно- } \\
\text { управленческой и коммуникационной деятельности } \\
\text { Уметь: выбирать правовые и нормативнотехнические до- } \\
\text { кументы, применяемые для решения заданий профессио- } \\
\text { нальной деятельности } \\
\text { Владеть: культурой мышления }\end{array}$ \\
\hline
\end{tabular}


Результаты обучения и оценочные средства дисциплины

\begin{tabular}{|l|l|}
\hline Результаты обучения по дисциплине & Оценочные средства \\
\hline $\begin{array}{l}\text { Знать: информационные ресурсы поиска информации } \\
\text { Уметь: осуществлять поиск информации, обобщать, анализировать и вос- } \\
\text { принимать информацию, ставить цель и выбирать пути ее достижения }\end{array}$ & Тесты 1, 2,3 и итоговый тест из раздела «Формирование отчетов», зачет \\
\hline $\begin{array}{l}\text { Знать: правовые и нормативно-технические документы научно-исследова- } \\
\text { тельского обеспечения организационно-управленческой и коммуникаци- } \\
\text { онной деятельности } \\
\text { Уметь: выбирать правовые и нормативнотехнические документы, применя- } \\
\text { емые для решения заданий профессиональной деятельности }\end{array}$ & \\
\hline \multicolumn{1}{|c|}{ Владеть: культурой мышления } & зачоговый тест из раздела «Создание презентаций», зачет \\
\hline
\end{tabular}

циплине [5]. Кроме того, в системе Moodle выложены тесты по двум разделам дисциплины, а также электронные версии ГОСТов и темы практических заданий в Excel, выполняемых в рамках раздела «Формирование отчетов». В вузовской системе Moodle также содержится перечень работ, выполняемых на практических занятиях по разделу «Создание презентаций» в MS PowerPoint и Publisher.

Следует отметить, что, начиная изучать дисциплину «Формирование отчетов и создание презентаций» на первом курсе, при подготовке к публичным выступлениям у студентов наблюдается развитие логического и аналитического мышления, формирование навыков последовательного и четкого распределения отчетных данных в презентации, что положительно отмечают преподаватели выпускающей кафедры. Положительные результаты внедрения с 2014 года данной дисциплины в образовательный процесс свидетельствуют об успешном опыте. Это подтверждается во время защиты выпускных квалификационных работ бакалаврами и отмечается в отчетах председателей ГАК.

В 2019 году дан старт 12-ти национальным проектам стратегического развития страны. Среди них национальный проект «Образование» ключевой целью, которого является обеспечение глобальной конкурентоспособности российского образования, что в дальнейшем повысит показатель индекса человеческого развития России в мировом рейтинге [3, с.176]. В связи с этим в Новосибирской открытой образовательной сети опубликованы цели регионального проекта по модернизации профессионального образования, включая разработку образовательных программ высшего и дополнительного образования с учетом потребностей заказчика [2]. Считаем, что содержание дисциплины «Формирование отчетов и создание презентаций» отвечает требованиям, связанными с владением средствами деловой и презентационной графики, поскольку зачастую они являются основой деловых совещаний, сопровождают публичные выступления и доклады, представляют перспективные или законченные проекты. Практический опыт показывает, что на различных конференциях и семинарах широко используются презентации, в которых отчет представлен в виде сводной таблицы, позволяющей детально проанализировать, комплексно изучить и обобщить данные.

В заключении следует отметить высокую значимость данной дисциплины в системе высшего образования в современных условиях, требующих формирования у студентов соответствующих компетенций. Считаем необходимым внедрение данной дисциплины в учебные планы как технических, так и гуманитарных направлений подготовки. Авторы статьи выражают готовность к сотрудничеству и оказанию методического, технологического содействия в организации теоретического и практического обучения студентов в подготовке, связанной с формированием отчетов и созданием презентаций на основе полученного опыта преподавания данной дисциплины в Сибирском государственном университете путей сообщения.

\section{ЛИТЕРАТУРА}

1. Болбат 0.Б. Дисциплина «Формирование отчетов и создание презентаций»: опыт внедрения в учебный процесс //Сборник статей Международной научно-практической конференции «Связь теории и практики научных исследований». 2016. С. 63-65.

2. Официальный сайт Национальный проект «Образование» http://www.edu54.ru/projects/npe/182683/

3. Хекало 0.Ю. Критерии оценки уровня жизни и развития человека в мировом пространстве // Экономика и бизнес: теория и практика. 2019. № 7. С. 176-178.

4. Хекало 0.Ю., Осипкова С.Е. проблемы и перспективы развития малого и среднего бизнеса в России // В сборнике: Проблемы развития предприятий: теория и практика Сборник статей VI Международной научно-практической конференции. 2019. С. 237-241. 
5. Болбат 0.Б., Петухова А.В., Андрюшина Т.В. Электронное учебно-методическое сопровождение дисциплин // Образовательные технологии и общество. 2019. T. 22. № 2. С. 78-84.

6. Электронный ресурс: http://moodle3.stu.ru

\section{๑ Болбат Ольга Борисовна (olgab2203@gmail.com), Закирова Елена Сергеевна (zes.64@mail.ru),} Хекало Ольга Юрьевна (new_holga@mail.ru).

Журнал «Современная наука: актуальные проблемы теории и практики»

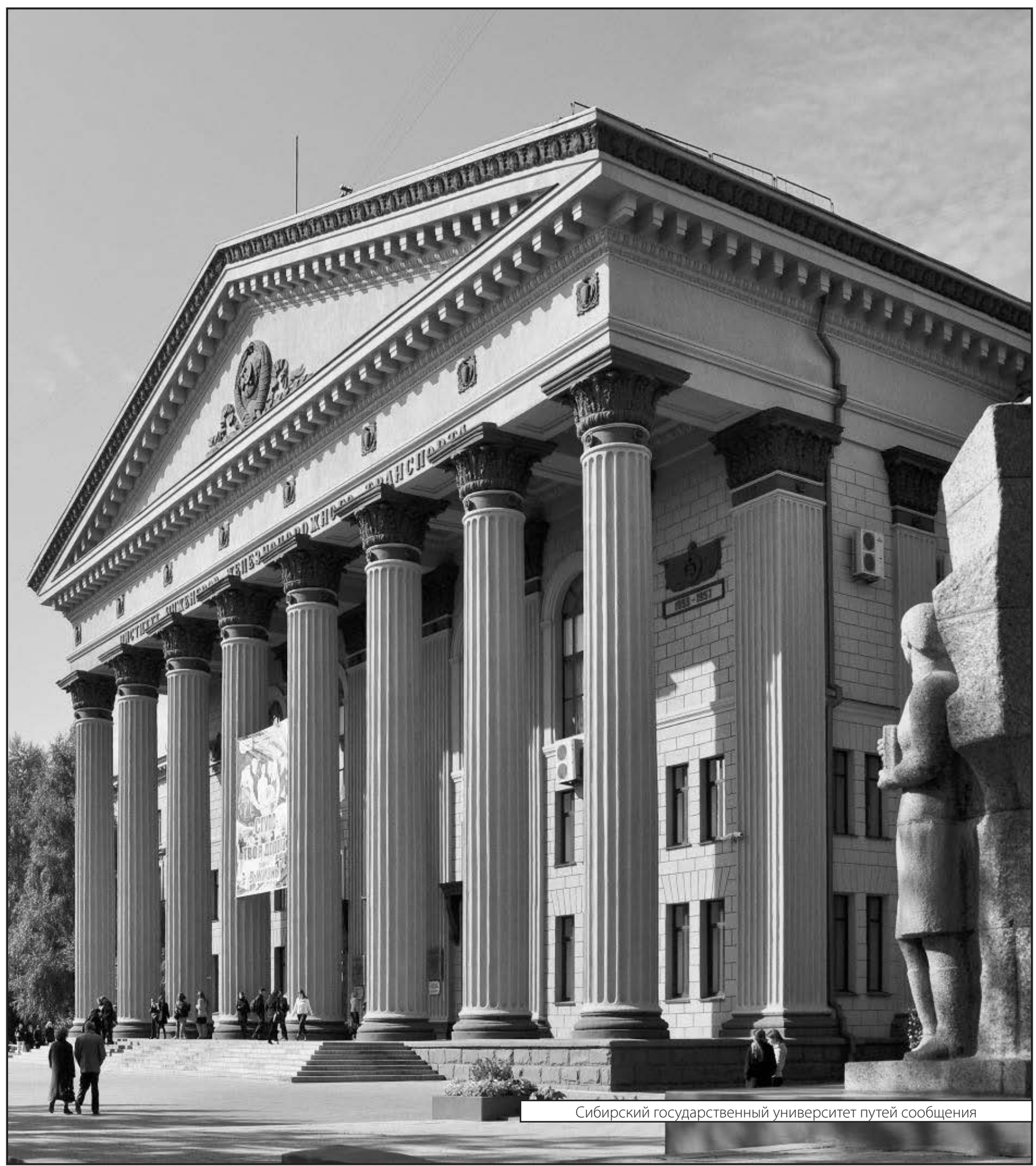

